\title{
Last witness and digital twin - physical and digital modelling the Munich Olympic Sports Hall - a case study
}

\author{
Baris Wenzel*, Eberhard Möller* \\ * Karlsruhe University of Applied Sciences, \\ 76133 Karlsruhe, Germany \\ e-mail: baris.wenzel@hs-kalsruhe.de - web page: http://www. hs-karlsruhe.de
}

\begin{abstract}
In the 20th century, innovative constructions were often developed and analyzed with the help of measurement models. Most of such physical models are lost today. Of the filigree measurement models for the Munich Olympic roofs, only that one of the sports hall remains as a last witness. ${ }^{[1]}$ This model is focused by a case study within the sub-project "The Last Witnesses" of the priority program "Cultural Heritage Construction" of the Deutsche Forschungsgemeinschaft DFG (German Research Foundation).

A digital twin will be created to examine the model, aspects like boundary conditions, the membrane-like load-bearing behavior of the cable net and the well-documented research results obtained at the $1970 \mathrm{~s}^{[2]}$. As the blatant opposite to the physical measuring device, for creating, recording and processing the digital twin, state-of-the-art means of the computer science are used. Additional to the standard process of reverse engineering by recording the inventory using a 3D scanner, the remodeling of the structure is done using algorithms and simultaneously the relevant data is collected and automatically fed into an open SQLite database by the use of a software written and developed especially for this project. The digital twin is also generated to simulate adaptations of loads by mutable factors like caused by climate change.

Further the database and the parametric 3D models can be used for multiple purposes all over the field of civil engineering as for example on the way to establish the history as an independent subject of research and teaching in the faculties of civil engineering or for organizing exhibitions or even museums about the works of civil engineering ${ }^{[3]}$.
\end{abstract}

\section{REFERENCES}

[1] E. Möller, Physical and measurement models for structural analysis - an endangered part of historical constructions, in: Proceedings of the 10th international conference on Structural Analysis of Historical Constructions, SAHC 2016, KU Leuven, Belgium, 13. - 15. Sept. 2016

[2] E. Möller, 92 Überdachung der Hauptsportstätten im Olympiapark München, in: W. Nerdinger (ed.): Frei Otto - Complete Works: Lightweight Construction - Natural Design, Basel Boston Berlin 2005, pp. 260-269

[3] E. Möller, Scale models for spatial structures from the 19th to the $21^{\text {st }}$ century, in: K. Kawaguchi, M. Ohsaki, T. Takeuchi (eds.), Proceedings of the IASS Annual Symposium 2016, Spatial Structures in the 21st Century, 26-30 Sept. 2016, Tokyo, Japan 